PREPARED FOR THE U.S. DEPARTMENT OF ENERGY, UNDER CONTRACT DE-AC02-76CH03073

PPPL-3619

PPPL-3619

UC-70

Advanced Tokamak Scenarios

for the FIRE Burning Plasma Experiment

by

C.E. Kessel, D. Ignat, and T.K. Mau

October 2001

NM|

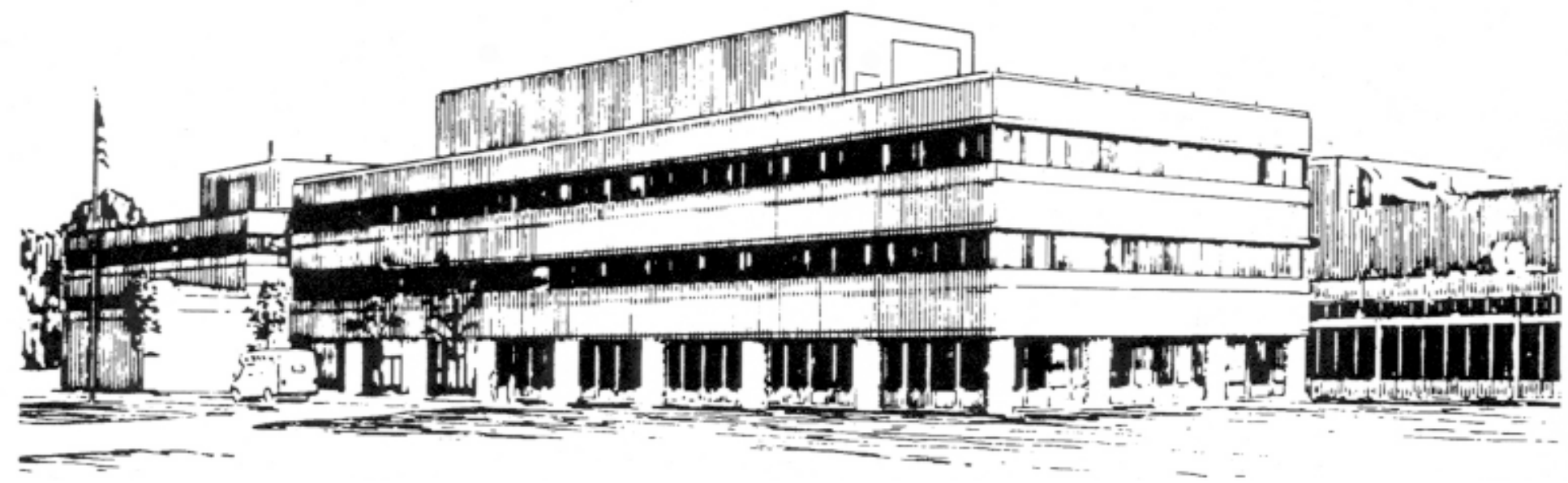

PRINCETON PLASMA PHYSICS LABORATORY PRINCETON UNIVERSITY, PRINCETON, NEW JERSEY 


\section{PPPL Reports Disclaimer}

This report was prepared as an account of work sponsored by an agency of the United States Government. Neither the United States Government nor any agency thereof, nor any of their employees, makes any warranty, express or implied, or assumes any legal liability or responsibility for the accuracy, completeness, or usefulness of any information, apparatus, product, or process disclosed, or represents that its use would not infringe privately owned rights. Reference herein to any specific commercial product, process, or service by trade name, trademark, manufacturer, or otherwise, does not necessarily constitute or imply its endorsement, recommendation, or favoring by the United States Government or any agency thereof. The views and opinions of authors expressed herein do not necessarily state or reflect those of the United States Government or any agency thereof.

\section{Availability}

This report is posted on the U.S. Department of Energy's Princeton Plasma Physics Laboratory Publications and Reports web site in FiscaL Year 2002. The home page for PPPL Reports and Publications is: http://www.pppl.gov/pub_report/

DOE and DOE Contractors can obtain copies of this report from:

U.S. Department of Energy

Office of Scientific and Technical Information

DOE Technical Information Services (DTIS)

P.O. Box 62

Oak Ridge, TN 37831

Telephone: (865) 576-8401

Fax: (865) 576-5728

Email: reports@adonis.osti.gov

This report is available to the general public from:

National Technical Information Service

U.S. Department of Commerce

5285 Port Royal Road

Springfield, VA 22161

Telephone: 1-800-553-6847 or

(703) 605-6000

Fax: (703) 321-8547

Internet: http://www.ntis.gov/ordering.htm 


\title{
Advanced Tokamak Scenarios for the FIRE Burning Plasma Experiment
}

\author{
C. E. Kessel, D. Ignat, and T. K. Mau*, Princeton Plasma Physics Laboratory, P.O.Box 451, \\ Princeton, NJ 08534, *Center for Energy Research, UCSD, 9500 Gilman Dr., LaJolla, CA, 92037
}

\begin{abstract}
The Advanced Tokamak capability of the FIRE burning plasma experiment is examined with OD systems analysis, equilibrium and ideal MHD stability, RF current drive analysis, and full discharge dynamic simulations. These analyses have identified the required parameters for attractive burning AT plasmas, and indicate that these are feasible with the present progress on existing experimental tokamaks.
\end{abstract}

\section{INTRODUCTION}

The Fusion Ignition Research Experiment (FIRE) is a high field compact tokamak burning plasma experiment, utilizing copper TF and PF coils. The project is examining the advanced tokamak (AT) capability of the device. The AT is envisioned as a sequence of configurations with progressively higher $\beta \mathrm{N}$, higher bootstrap/noninductive current fraction, for extended pulse lengths, and with more sophisticated plasma control. In order to obtain extended pulse lengths the toroidal field is lowered, providing flattop times of $31 \mathrm{~s}$ at $9 \mathrm{~T}, 44 \mathrm{~s}$ at $8 \mathrm{~T}$, and $65 \mathrm{~s}$ at $7 \mathrm{~T}$. Increasing $\beta \mathrm{N}$ requires first stabilizing the neoclassical tearing modes, allowing access to $\beta \mathrm{N}$ above 2.0-2.5. Stabilization of the $n=1$ resistive wall mode allows access to $\beta \mathrm{N}$ values above 3.0-3.5. Stabilization of $\mathrm{n}>2$ resistive wall modes would allow access to higher $\beta \mathrm{N}$ values. The bootstrap/noninductive current fraction is increased by raising the $\beta \mathrm{N}$, using external current drive sources (ICRF/FW, LHCD), and control of the density and temperature profiles. The control of temperature and density profiles inside the plasma is directly tied to research on internal transport barriers (ITB), and is an active area for tokamak theory and experiments.

The primary focus of AT scenarios for FIRE are quasistationary burning plasmas. The plasma current is to be driven noninductively in flattop, although inductive drive is used in conjunction with noninductive current drive during the rampup. The plasma safety factor is required to be quasistationary for the flattop phase, and held by the combination of bootstrap current, and lower hybrid and fast wave current drive sources. The flattop times obtained by lowering the toroidal field are typically 2-4 times the current diffusion time in these plasmas. Since these are burning plasmas, the target is fusion gains $(\mathrm{Q}=$ Pfus/Paux $)$ of 5-10.

\section{SYSTEMS ANALYSIS OF ADVANCED TOKAMAK PLASMAS}

A zero-dimensional systems code was developed for use in the FIRE study. This analysis incorporates the plasma, the TF magnet inboard legs, and the $\mathrm{OH}$ solenoid, all affecting the radial build of the device. The plasma section includes power and particle balance, plasma flux consumption, in addition to several other global parameter relations. In particular, the
ITER98(y,2) scaling is assumed for the global energy confinement time. The TF and $\mathrm{OH}$ coil sections calculate temperature and stress to compare with allowables set by the materials used. The code is typically used to find the minimum major radius for a set of input parameters, such as toroidal field, q95, Q, density profile, flattop time, etc. However for the present application to AT plasmas, the major and minor radius, and elongation, triangularity and aspect ratio are fixed. These have been set by the reference ELMy Hmode inductively driven design point; $\mathrm{R}=2.0 \mathrm{~m}, \mathrm{a}=0.53 \mathrm{~m}$, $\kappa(\mathrm{Xpt})=2.0, \quad \delta(\mathrm{Xpt})=0.7, \mathrm{~A}=3.8 . \quad$ An expression for the bootstrap current fraction is included and the current drive power is given by $\mathrm{Pcd}_{\mathrm{cd}}=[\mathrm{nRI} \mathrm{p}(1-\mathrm{fbs})] / \eta_{\mathrm{cd}}$. A large number of plasma configurations are generated by varying the toroidal field (from 6.5-9.5 T), q95 (from 3.1-4.7), peak to average density (from 1.25 to 2.0 ), $\beta \mathrm{N}$ (from $2.5-4.5$ ), and density divided by Greenwald density $\mathrm{n} / \mathrm{n}$ Gr (from $0.45-0.85$ ). Here the Greenwald density is defined as $\mathrm{nGr}=\mathrm{Ip} / \pi \mathrm{a}^{\wedge} 2$ The acceptable solutions are constrained to have a given $\mathrm{Q}$ value, the external current drive power must be less than the total auxiliary power injected into the plasma, and the fusion power must be less than $250 \mathrm{MW}$. The current drive efficiency used in these scans is $\eta \mathrm{cd}=0.45 \mathrm{~A} / \mathrm{W}-\mathrm{m} 2$ and is based on detailed LH and ICRF/FW analysis for FIRE.

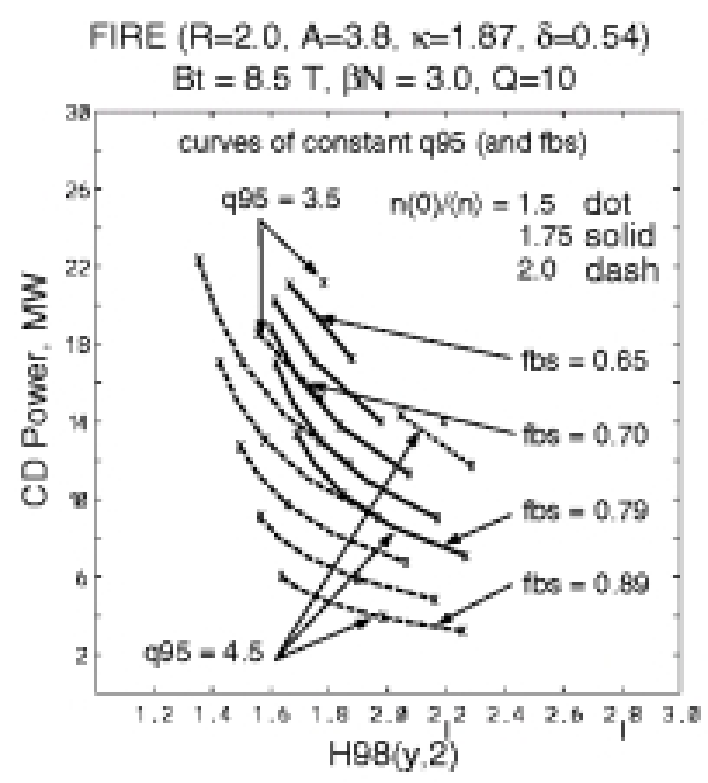

FIGURE 1. The required current drive power versus the required $\mathrm{H}(*$ confinement multiplier for plasmas at $\mathrm{Bt}=8.5 \mathrm{~T}, \beta \mathrm{N}=3.0$, nd $\mathrm{Q}=10$. Three peak to average densities, and several $\mathrm{q} 95$ and $\mathrm{fb}$ values are displayed, showing accessible plasmas in the device. Similar curves would exist for other values of $\mathrm{Bt}, \beta \mathrm{N}$, and $\mathrm{Q}$.

Shown in Figure 1 is the current drive power as a function of the $\mathrm{H} 98$ factor, for specific values of $\mathrm{Bt}=8.5 \mathrm{~T}, \beta \mathrm{N}=3.0$, and $\mathrm{Q}=10$. The plot shows curves of constant $\mathrm{q} 95$, which are also constrant bootstrap current fraction. In addition, curves 
for different values of the peak to average density are shown. The major conclusions from this analysis are that $\mathrm{Q}=10$ is difficult to achieve without H98 factors exceeding 1.4. The peaking of the density is a high leverage quantity both for plasma power balance and for increasing the bootstrap current fraction. Although higher $\mathrm{n} / \mathrm{nGr}$ improves power balance allowing lower H98 factors, it increases the current drive power, since noninductive sources of current are more efficient at high temperature and low density. In order to obtain a given $\beta \mathrm{N}$ with the lowest required H98 there exists an optimum combination of $\mathrm{Bt}$ and q95. For example, a toroidal field of $8.5 \mathrm{~T}$ and $\mathrm{q} 95$ of 3.7 provide the lowest $\mathrm{H} 98$ factor, equal to 1.35 for $\beta \mathrm{N}=3.0$, which is shown in the figure.

\section{PLASMA EQUILIBRIUM AND STABILITY}

Equilibrium and ideal MHD stability analyses are done to determine what plasmas can be produced and what their achievable $\beta$-limits are. The JSOLVER[1] fixed boundary flux coordinate equilibrium code is used with self-consistent bootstrap current. The BALLOON[2] and PEST2[3] codes are used for $n=$ infinity and $n=1-3$ stability calculations, respectively. In addition, the VACUUM code is used to treat the presence of the vacuum vessel.

The plasma configurations all have reversed shear[4] current and safety factor profiles. It is found that $\beta \mathrm{N}$ maximizes when the minimum in the safety factor, $\mathrm{q}(\mathrm{min})$, is between $1.2-1.5$ and 2.1-2.3, which has been observed before in theoretical analysis[5]. The location of this minimum determines the maximum plasma current achievable, the closer toward the plasma edge, the larger the plasma current. There is also a pressure profile dependence that gives the highest $\beta \mathrm{N}$. The configurations with $\mathrm{q}(\mathrm{min})$ around 1.35 were found to have $\beta_{\mathrm{N}}$ values of $3.2-3.6$, set by the $\mathrm{n}=1$ external kink mode. However, they will have low order NTM s which must be stabilized at the $(3,2)$ and $(2,1)$ flux surfaces. The $n=2$ kink $\beta$-limits turn out to be at the same values as that for $n=1$, ignoring the influence of the vacuum vessel. The bootstrap current fractions ranged from 0.35 to 0.5 . For the $q(\mathrm{~min})$ about 2.15 the $\beta \mathrm{N}$ values ranged from 2.5 to 3.0 , the higher values obtained when $\mathrm{q}(\mathrm{min})$ was located closer to the plasma center, and visa versa. These are again set by the $n=1$ external kink mode in the absense of the vacuum vessel. For these cases the $\mathrm{n}=2$ kink $\beta$-limits ranged from 3.4 to 3.6 , which were higher than the $n=1$ limits. The NTM s that would have to be stabilized are higher order since the safety factor is above 2.0 everywhere, these being the $(5,2)$ and $(3,1)$, and are presumed to be less dangerous. The bootstrap current fractions ranged from 0.5 to 0.65 .

Subsequent LHCD analysis indicated that current deposition could not be achieved inside of a normalized minor radius of 0.6 , or that the peak could not get deeper than 0.8 , for typical FIRE temperatures and densities. Based on this the reference AT plasma is taken to have $\mathrm{q}(\mathrm{min})=2.1, \mathrm{r} / \mathrm{a}(\mathrm{qmin})=0.8$, with $\beta \mathrm{N}=2.5$ set by the $n=1$ kink mode. In the presence of actual conducting structures, like the vacuum vessel, this kink mode transforms into the resistive wall mode. Stabilization of the $n=1$ RWM is being actively pursued on the DIII-D tokamak experiment[6]. Shown in Figure 3 is the achievable $\beta \mathrm{N}$ both ignoring the vacuum vessel s influence and including it with various approximations. The curve labelled no wall refers to no conductors outside the plasma, and gives the $\beta$ limits reported above. The curve labelled full wall refers to a toroidally continous superconducting wall covering the outboard side of the plasma, spanning the poloidal angles of $+90^{\circ}$ to $-90^{\circ}$, measured from the plasma major radius. This provides the best values achievable. However, the actual vacuum vessel has penetrations and is a resistive material. Trying to represent the penetrations, but still with a superconducting wall provides the $\beta$-limits noted by partial walls, and are simplified models of the VV. Finally, the 3D electromagnetics code VALEN[7] is used to represent the vacuum vessel accurately and include the effects of feedback coils, and predicts a maximum $\beta_{\mathrm{N}}$ of 3.75 with feedback stabilization of the $n=1$ RWM. In this case, the feedback scheme involves placing feedback window coils around the periphery of each/or every other midplane port. Further VALEN and PEST2 analysis will refine the feedback coil schemes to stabilize the $n=1$ RWM, and determine the impact of the $n=2$ mode. The access to the higher $\beta \mathrm{N}$ by $\mathrm{RWM}$ stabilization allows the bootstrap current fraction to reach 0.75 , and would provide an attractive example of a burning AT plasma.

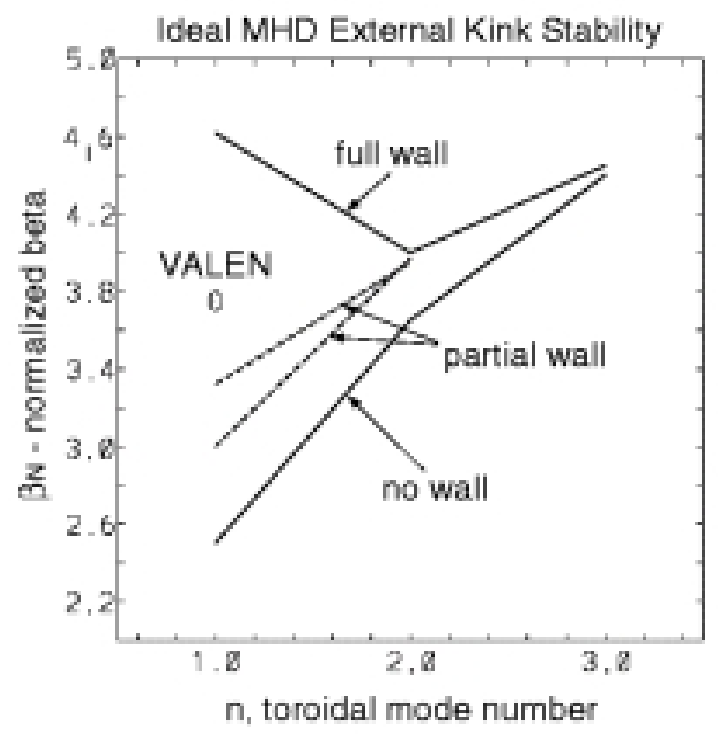

Figure 2. Maximum $\beta \mathrm{N}$ values for the $\mathrm{n}=1-3$ external kink modes showing the influence of various approximations to the surrounding conductors.

\section{RF CURRENT DRIVE ANALYSIS}

Current drive calculations have been done for lower hybrid and ICRF fast wave schemes. Neutral beam injection is not presently part of the current drive capability for FIRE, however, it is still being considered for heating/current drive/rotation due to its importance in present experiments for 
MHD stability, transport, and diagnostics. Electron cyclotron heating is desirable for startup, however, the high densities and fields in FIRE make its application to current drive difficult. Only LH and FW will be discussed in the following.

Preliminary analysis of the ICRF fast wave current drive was done at two extremes. The first approach assumed all the launched power was in the good part of the parallel wave spectrum which would lead to current drive in the direction of the plasma current. The frequency used was $110 \mathrm{MHz}$, nparallel was 2.0 , peak density was $3.4 \times 10^{\wedge} 20 / \mathrm{m}^{\wedge} 3$, peak temperature was $20 \mathrm{keV}$, and the Zeff was 1.4 with $\mathrm{Be}$ as the impurity. This resulted in $300 \mathrm{kA}$ of current driven at the plasma center with $3.6 \mathrm{MW}$ of injected power, or $0.083 \mathrm{~A} / \mathrm{W}$.

The second approach assumed that $40 \%$ of the power was in the good part of the parallel wave spectrum, a frequency of 115 MHz, n-parallel was 2.0 , a peak density of $5.0 \times 10^{\wedge} 20 / \mathrm{m}^{\wedge} 3$, and a peak temperature of $14 \mathrm{keV}$. This results in $600 \mathrm{kA}$ of current driven by $30 \mathrm{MW}$ of injected power, or $0.02 \mathrm{~A} / \mathrm{W}$. In the second case there was significant alpha particle absorption, due to the choice of $115 \mathrm{MHz}$ which causes the fast wave to cross the He4 resonance. From the equilibrium calculations total $\mathrm{FW}$ current requirements at the plasma center ranged from $150-400 \mathrm{kA}$. In both cases the fast wave power is being absorbed by ions, as well as the electrons, due to the weak single pass absorption. The actual CD efficiency is expected to fall between these values. Future work will concentrate on antenna design to maximize the launched power into the good part of the wave spectrum for current drive, more precise choice of frequency to minimize ion absorption, and examination of several AT operating points.

The lower hybrid current drive calculations were done with LSC[8]. The minimum frequency was chosen to be above twice the lower hybrid frequency for the largest field expected, which is $3.5 \mathrm{GHz}$. Values used in the analysis were 4.6 and $5.6 \mathrm{GHz}$, the former being that chosen for the Alcator C-Mod launcher. The parallel wave spectrum was chosen to minimize mode conversion at low $\mathrm{n} \|$, while trying to get the deepest penetration. The spectrum is peaked at $\mathrm{n} \|=2.0$. The width of the spectrum was taken at 0.3 , which was also typical of that expected from the C-Mod design. For a peak density of $4.5 \times 10^{\wedge} 20 / \mathrm{m}^{\wedge} 20$, a peak temperature of $22 \mathrm{keV}$, peak to average density of 1.5 , and toroidal field of $8.5 \mathrm{~T}$, there was 1.7 MA of current driven for $20 \mathrm{MW}$ of injected power, giving $0.085 \mathrm{~A} / \mathrm{W}$. Several spectrum variations were analyzed, as well as several density and temperature variations. The LH current deposition can be seen in Figure 4. The lower hybrid deposition does reach the tail of the alpha particle birth profile, and absorption by the alpha particles would be expected. It is possible that these alpha particles will be lost due to ripple effects, mitigating this concern.

In addition to the off-axis current drive source for AT plasmas in FIRE, the LHCD is being examined for stabilization of the neo-classical tearing modes. It has been demonstrated experimentally[9] and theoretically[10] that LH waves could stabilize NTMs through local modification of the current profile providing a more negative $\Delta^{\prime}$ (than the original current profile) in the vicinity of the island. The TSC-LSC code has been used to simulate the effect for the FIRE baseline configuration and the $(3,2)$ island. Although the LHCD scheme can be demonstrated on FIRE, due to the current drive efficiency for LHCD at the typical densities for FIRE, this approach appears most feasible if the LHCD is part of the main current drive scheme, not as a highly localized source.

\section{DYNAMIC EVOLUTION OF ADVANCED TOKAMAK PLASMAS}

The Tokamak Simulation Code[11] (TSC) is used to simulate the discharge, with the LSC ray tracing package connected for the lower hybrid current drive calculations. The fast wave is not calculated self-consistently, but modelled as a prescribed profile and current drive efficiency. The primary goal is to establish quasi-stationary burning plasmas for the flattop, where the current and safety factor profiles do not significantly change. Although inductive and non-inductive current drive are used to ramp the plasma current up, the flattop plasma has $100 \%$ non-inductive current provided by the combination of bootstrap, lower hybrid, and fast wave current.

The parameters for this simulation are $\mathrm{Bt}=8.5 \mathrm{~T}, \mathrm{Ip}=5.5$ $\mathrm{MA}, \beta \mathrm{N}=3.0, \beta=4.4 \%, \mathrm{I}(\mathrm{BS})=3.5 \mathrm{MA}, \mathrm{I}(\mathrm{LH})=1.7 \mathrm{MA}$, $\mathrm{I}(\mathrm{FW})=0.35 \mathrm{MA}$, and $\mathrm{Q}=7.5$ with $\mathrm{H} 98(\mathrm{y}, 2)=1.6$. The plasma current is ramped up over $10 \mathrm{~s}$, and the flattop is $32 \mathrm{~s}$ long. Shown in Figures 5-7 are some time histories for this simulation. A maximum of $15 \mathrm{MW}$ of ICRF power, to drive the small on axis current and heat the plasma, is injected during the rampup, and dropped to $5 \mathrm{MW}$ in the flattop. The LH power increases to $20 \mathrm{MW}$ during rampup and remains there for the flattop. This provides both off-axis current drive and heating to electrons. The density relative to Greenwald density reaches 0.45 , with the peak density reaching $4.7 \times 10^{\wedge} 20 / \mathrm{m}^{\wedge} 3$, and with a peak to average density of 1.5 . The energy confinement time in flattop is $0.6 \mathrm{~s}$, which is 1.6 times the ITER98(y,2) scaling. The peak electron temperature reaches $21 \mathrm{keV}$, while that for the ions is $17.5 \mathrm{keV}$, and the peak to average temperatures for both species is 2.0. About 20 $\mathrm{V}$-s were used in the plasma current rampup, which is about $55 \%$ of that required to ramp to the full current inductively. The flattop alpha power was $37 \mathrm{MW}$, with $5 \mathrm{MW}$ of ICRF and $20 \mathrm{MW}$ of LH. The bremsstrahlung radiation loss was 6.3 MW. The impurity is taken to be $3 \% \mathrm{Be}$, which resulted in a Zeff of 1.41 with the He included. The volume average He density was $1.82 \times 10^{\wedge} 19 / \mathrm{m}^{\wedge} 3$. The bootstrap current fraction is $63 \%$, with $\mathrm{LH}$ providing $31 \%$ and $\mathrm{FW}$ the remaining $6 \%$. The high bootstrap fraction is due to a $\beta \mathrm{N}$ of 3.0 in combination with a stronger density peaking than is typical of standard ELMy H-modes. Although pellet fueling might provide some peaking, it is expected that the formation of an internal transport barrier will provide more significant peaking. Transport calculations to predict the formations of an 
ITB are underway. The density peaking is also important for efficient LH current drive, whose efficiency scales as $\mathrm{T} / \mathrm{n}$, by keeping the density lower in the deposition region.

\section{DISCUSSION}

The FIRE burning plasma design, based on the fully inductive ELMing H-mode plasma configuration, is capable of producing a wide range of AT plasma configurations, with $\mathrm{Q}=5-10$ and $\mathrm{Pcd}<25 \mathrm{MW}$, assuming that progress on experimental tokamaks continues in confinement improvement, NTM and RWM stabilizaton, and internal transport barrier control. Systems analysis shows the importance of density peaking and operation near the Greenwald density limit for accessing high $\mathrm{Q}$ with reasonable H98 factors. AT burning plasma solutions must meet constraints set by power balance and current drive. Equilibrium and ideal MHD stability analysis have identified attractive AT targets, and future work will include more detailed variations. The RF current drive analysis has demonstrated that FWCD and LHCD are viable noninductive current sources for FIRE s plasma parameters, and future work will be focused on more detailed antenna design and operating scenarios. The dynamic simulations have demonstrated that a combination of inductive and noninductive current drive can rampup the plasma current, resulting in a fully noninductive quasi-stationary flattop plasma in timescales that are provided by the cryogenic copper TF/PF coils used in FIRE. Future work will include transport modelling to include affects of pedestals and internal transport barriers on AT plasmas.

\section{REFERENCES}

[1] J. DeLucia, S. C. Jardin, and A. M. M. Todd, An Iterative Metric Method for Solving the Inverse Tokamak Equilibrium Problem, J. Comp. Phys., vol. 37, pg. 183, 1980.

[2] J. M. Greene and M. S. Greene, The Second Region of Stability Against Ballooning Modes, Nucl. Fusion, vol. 21, pg. 453, 1981

[3] R. C. Grimm, R. L. Dewar, and J. Manickam, Ideal MHD Stability Calculations in Axisymmetric Toroidal Coordinate Systems, J. Comp. Phys., vol. 49, pg. 94, 1983.

[4] C. E. Kessel, J. Manickam, G. Rewoldt, and W. Tang, Improved Plasma Performance in Tokamaks with Negative Magnetic Shear, Phys. Rev. Lett., vol. 72, pg. 1212, 1994.

[5] A. Bondeson, M. Benda, M. Persson, and M. S. Chu, Magnetohydrodynamic Beta Limits for Tokamaks with Negative Central Shear, Nucl. Fusion, vol. 37, pg. 1419, 1997.

[6] M. Okabayashi, et al., Active Feedback Stabilization of the Resistive Wall Mode on the DIII-D Device, Phys. Plasmas, vol. 8, pg. 2071, 2001.

[7] J. Bialek, A. H. Boozer, M. E. Mauel, and G. A. Navratil, Modelling of Active Control of External Magnetohydrodynamic Instabilities, Phys. Plasmas, vol. 8, pg. 2170, 2001.

[8] D. W. Ignat, E. J. Vleo, and S. C. Jardin, Dynamic Modelling of Lower Hybrid Current Drive, Nucl. Fusion, vol. 34, pg. 837, 1994.

[9] C. D. Warrik, et al., Complete Stabilization of Neoclassical Tearing Modes ith Lower Hybrid Current Drive on COMPASS-D, Phys. Rev. Lett., vol. 85, pg. 574, 2000.

[10] A. Pletzer and F. W. Perkins, Stabilization of Neoclassical Tearing Modes Using a Continuous Localized Current Drive, Phys. Plasmas, vol. 6, pg. 1589, 1999.

[11] S. C. Jardin, N. Pomphrey, and J. Delucia, Dynamic Modelling of Transport and Position Control of Tokamaks, J. Comp. Phys., vol. 66, pg. 481, 1986.
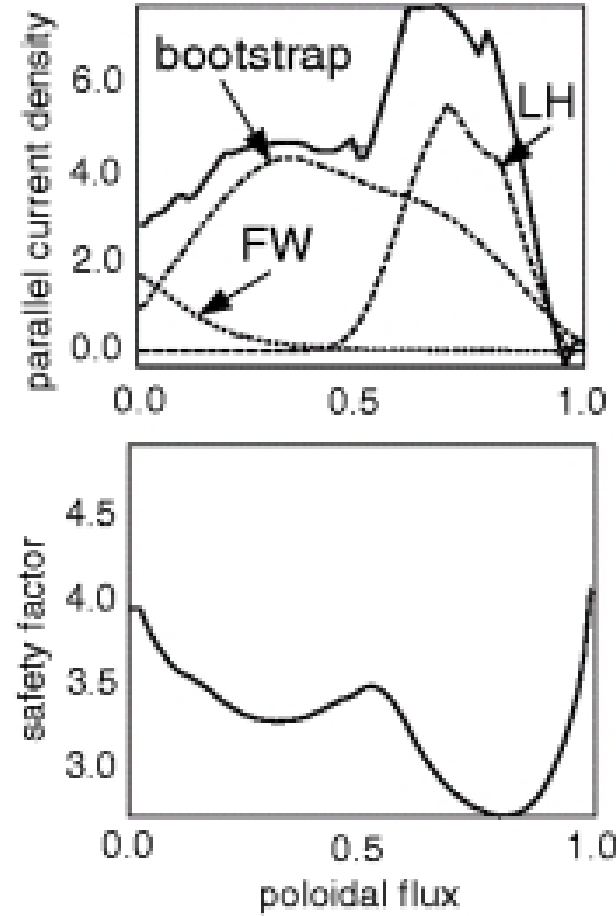

Figure 3. The parallel current density profile from the TSC-LSC AT simulation during flattop, showing the $\mathrm{LH}, \mathrm{FW}$, ann bootstrap current profiles. The resulting safety factor profile is also shown.
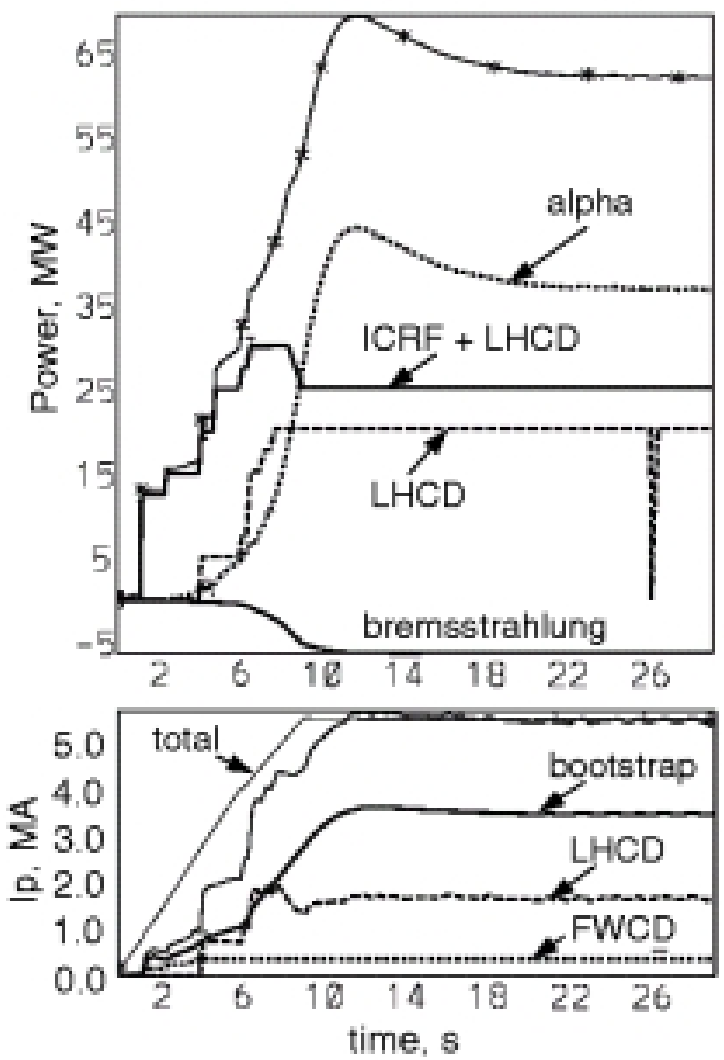

Figure 4. Time histories from the TSC-LSC AT simulation, of the various contributions to the plasma current and the powers injected into the plasma. The simulation is stopped after $29 \mathrm{~s}$ since to expand the rampup phase. 


\section{External Distribution}

Plasma Research Laboratory, Australian National University, Australia

Professor I.R. J ones, Flinders University, Australia

Professor J oão Canalle, Instituto de Fisica DEQ/IF - UERJ , Brazil

Mr. Gerson O. Ludwig, Instituto Nacional de Pesquisas, Brazil

Dr. P.H. Sakanaka, Instituto Fisica, Brazil

The Librarian, Culham Laboratory, England

Library, R61, Rutherford Appleton Laboratory, England

Mrs. S.A. Hutchinson, JET Library, England

Professor M.N. Bussac, Ecole Polytechnique, France

Librarian, Max-Planck-Institut für Plasmaphysik, Germany

J olan Moldvai, Reports Library, MTA KFKI-ATKI, Hungary

Dr. P. Kaw, Institute for Plasma Research, India

Ms. P.J . Pathak, Librarian, Insitute for Plasma Research, India

Ms. Clelia De Palo, Associazione EURATOM-ENEA, I taly

Dr. G. Grosso, Instituto di Fisica del Plasma, Italy

Librarian, Naka Fusion Research Establishment, J AERI, J apan

Library, Plasma Physics Laboratory, Kyoto University, J apan

Research Information Center, National Institute for Fusion Science, J apan

Dr. O. Mitarai, Kyushu Tokai University, J apan

Library, Academia Sinica, Institute of Plasma Physics, People's Republic of China

Shih-Tung Tsai, Institute of Physics, Chinese Academy of Sciences, People's Republic of China

Dr. S. Mirnov, TRINITI, Troitsk, Russian Federation, Russia

Dr. V.S. Strelkov, Kurchatov Institute, Russian Federation, Russia

Professor Peter Lukac, Katedra Fyziky Plazmy MFF UK, Mlynska dolina F-2, Komenskeho Univerzita, SK-842 15 Bratislava, Slovakia

Dr. G.S. Lee, Korea Basic Science Institute, South Korea

Mr. Dennis Bruggink, Fusion Library, University of Wisconsin, USA

Institute for Plasma Research, University of Maryland, USA

Librarian, Fusion Energy Division, Oak Ridge National Laboratory, USA

Librarian, Institute of Fusion Studies, University of Texas, USA

Librarian, Magnetic Fusion Program, Lawrence Livermore National Laboratory, USA

Library, General Atomics, USA

Plasma Physics Group, Fusion Energy Research Program, University of California at San Diego, USA

Plasma Physics Library, Columbia University, USA

Alkesh Punjabi, Center for Fusion Research and Training, Hampton University, USA

Dr. W.M. Stacey, Fusion Research Center, Georgia Institute of Technology, USA

Dr. J ohn Willis, U.S. Department of Energy, Office of Fusion Energy Sciences, USA

Mr. Paul H. Wright, Indianapolis, Indiana, USA 
The Princeton Plasma Physics Laboratory is operated by Princeton University under contract with the U.S. Department of Energy.

\author{
Information Services \\ Princeton Plasma Physics Laboratory \\ P.O. Box 451 \\ Princeton, NJ 08543
}

Phone: 609-243-2750

Fax: 609-243-2751

e-mail: pppl_info@pppl.gov

Internet Address: http://www.pppl.gov 